\title{
Availability of Farmers' Markets and Supplemental Nutrition Assistance Program/Electronic Benefit Transfer Systems and Associations With Rurality, Poverty, Race/Ethnicity, and Obesity Among North Carolina Counties
}

SALLY LAWRENCE BULLOCK, ${ }^{1}$ STEPHANIE B. JILCOTT PITTS, ${ }^{2}$ BARB LISTENFELT, ${ }^{3}$ JARED T. MCGUIRT, ${ }^{1}$ KAREN STANLEY, ${ }^{3}$ DIANE BETH, ${ }^{3}$ MARY BEA KOLBE, ${ }^{3}$ JILL RUSHING,${ }^{3}$ QIANG WU, ${ }^{4}$ RACHEL

K. WARD,$^{5}$ MARIEL LEAH MAYO ACHESON,${ }^{6}$ CIARRA J. M.

DORTCHE, ${ }^{2}$ and ALICE S. AMMERMAN ${ }^{7}$

${ }^{1}$ UNC Center for Health Promotion and Disease Prevention, Chapel Hill, North Carolina, USA ${ }^{2}$ East Carolina University, Brody School of Medicine, Department of Public Health, Greenville, North Carolina, USA

${ }^{3}$ North Carolina Division of Public Health, Raleigh, North Carolina, USA

${ }^{4}$ Department of Biostatistics, East Carolina University, Greenville, North Carolina, USA ${ }^{5}$ East Tennessee State University, Department of Community Health, Johnson City, Tennessee, USA

${ }^{6}$ Region 9 Community Transformation Grant Project, Elizabeth City, North Carolina, USA

${ }^{7}$ Department of Nutrition, Gillings School of Global Public Health, Center for Health Promotion and Disease Prevention, University of North Carolina at Chapel Hill, Chapel Hill, North Carolina, USA

Increasing the number of farmers' markets and implementing Electronic Benefit Transfer (EBT) systems for the Supplemental Nutrition Assistance Program (SNAP) at more farmers' markets have been suggested as strategies to overcome food access issues, but little is known about their availability in the rural South. This study examines differences in availability of farmers' markets and $S N A P / E B T$ at markets by county-level rural/urban classification,

Address correspondence to Sally Lawrence Bullock, UNC Center for Health Promotion and Disease Prevention, CB\# 7426, 1700 MLK Jr. Blvd., Chapel Hill, NC 27599-7426, USA. E-mail: sallylb@live.unc.edu 
percentage poverty, percentage racial/ethnic minority, and percentage obese residents in North Carolina counties. Data were collected using a cross-sectional survey. Though results related to rurality and economic status are mixed, regression analyses indicate that the percentage of African American residents is inversely associated with the number of markets and number of markets that accept EBT. Results suggest that access to farmers' markets varies in North Carolina, and additional research is needed to determine whether this impacts obesity.

KEYWORDS food environment, food access, farmers' markets, North Carolina, Supplemental Nutrition Assistance Program (SNAP)

\section{INTRODUCTION}

Obesity prevalence among adults and children in the United States is higher in rural areas than urban and suburban areas. ${ }^{1-3}$ Obesity has been linked to a variety of chronic diseases, ${ }^{4-6}$ and residents of rural areas have higher chronic disease rates than residents of nonrural areas. ${ }^{7-9}$ In many Southern states, including North Carolina, rural areas are also those with high poverty levels and more racial and ethnic minority residents. ${ }^{10,11}$ Individuals of low socioeconomic status and racial/ethnic minorities may also be at higher risk for obesity. $3,12,13$

The differences in obesity prevalence in rural and urban areas may be due in part to lower access to healthy food options in rural areas. Previous studies have found that rural residents and residents of low-income and minority communities have less access to supermarkets and grocery stores than urban/suburban residents ${ }^{14-19}$ and that lack of access to healthy foods is associated with poorer dietary habits and obesity. ${ }^{18,20-25}$ Increasing the number of farmers' markets and other outlets that sell primarily produce has been suggested as a strategy to overcome food access issues in rural areas and provide fresh produce to rural residents, who often live far from supermarkets and grocery stores. ${ }^{15,26}$ Implementing Electronic Benefit Transfer (EBT) systems that allow Supplemental Nutrition Assistance Program (SNAP) participants to use their benefits at farmers' markets has also been suggested as a strategy to enhance access to fruits and vegetables in low-income communities. ${ }^{27,28}$ However, little is known about the availability of farmers' markets and EBT payment options at farmers' markets in the rural South.

North Carolina is a southern state with a long agricultural history. According to the 2010 census, $40 \%$ of North Carolina's population is found in rural areas, making it the 12th most rural state in the nation. ${ }^{29}$ As of 2011 , the self-reported prevalence of adult obesity in North Carolina was 29.6\%. 


\section{North Carolina Fruit and Vegetable Outlet Inventory, Farmers' Markets by County}

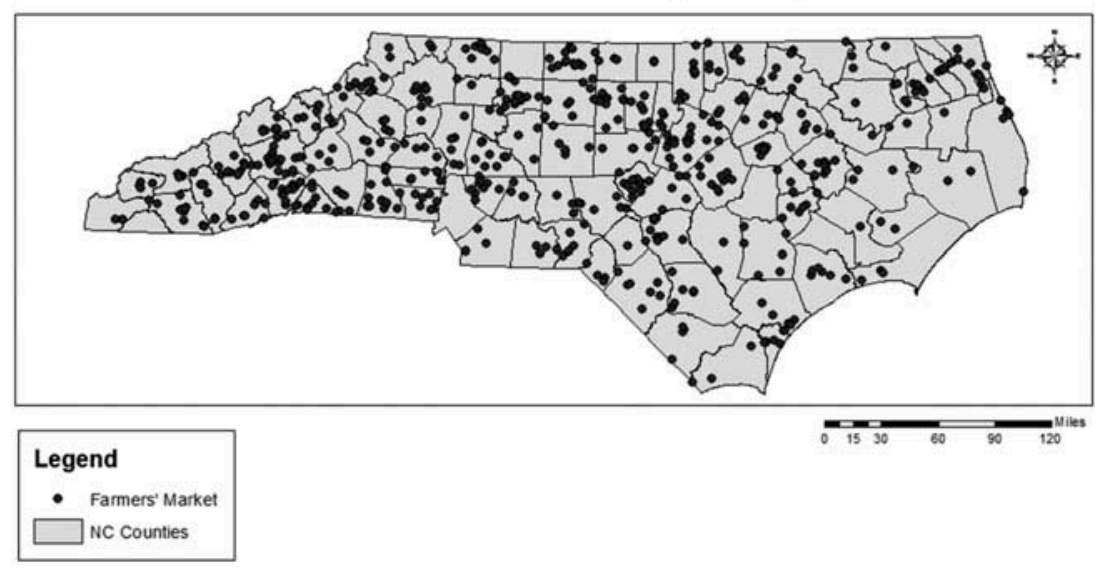

FIGURE 1 Availability of farmers' markets and Supplemental Nutrition Assistance Program/Electronic Benefits Transfer systems and associations with rurality, poverty, race/ethnicity, and obesity among North Carolina counties.

County-level adult obesity prevalence in 2010 ranged from 20.8\% (Orange County) to $40.7 \%$ (Robeson County). The self-reported prevalence of adult diabetes in North Carolina in 2010 was 9.8\%, and the county-level prevalence ranged from $6.7 \%$ (Orange County) to 16.1\% (Halifax County). Obesity prevalence among 2- to 4-year-olds from low-income families in North Carolina was $15.4 \%$ in 2011, and the county-level prevalence (2009-2011) ranged from $8 \%$ (Cumberland County) to $22.3 \%$ (Pender County). ${ }^{30}$ The extent to which these levels of obesity and diabetes in North Carolina might be explained by different levels of access to healthy food options and, in particular, to farmers' markets is unclear.

In order to address this uncertainty, we examined differences in North Carolina farmers' market availability and SNAP/EBT payment options at farmers' markets by county-level rural/urban classification, percentage poverty, percentage ethnic/racial minority, and county-level obesity and diabetes rates. Though there are multiple definitions for a "farmers' market," ${ }^{\text {"28,31 for }}$ the purposes of this article, we define a farmers' market as an outlet with a predictable location and hours of operation that sells produce onsite and is not a retail store or community-supported agriculture/buying club program (see Figure 1). This definition of a farmers' market includes but is not limited to roadside markets, roadside stands, farm stands, tailgate markets, and other similar outlets that sell produce directly to consumers. Though some organizations specify that a farmers' market is a multistall market where farmers sell agricultural products directly to the general public, ${ }^{31}$ not all outlets that refer to themselves as farmers' markets are run by farmers and not all farmer-run outlets are a part of a multistall market. 
We hypothesize that in both absolute numbers and per capita, (1) rural counties have fewer farmers' markets and fewer farmers' markets with SNAP/EBT compared to urban counties, (2) counties with a greater percentage of residents living in poverty have fewer farmers' markets and fewer farmers' markets with SNAP/EBT compared to counties with a lower percentage of residents living in poverty, (3) counties with higher racial and ethnic minority populations have fewer farmers' markets and fewer farmers' markets with SNAP/EBT compared to those with lower ethnic and minority populations, and (4) counties with more farmers' markets have lower obesity and diabetes rates.

\section{METHODS}

\section{Study Setting}

In 2011, the North Carolina Division of Public Health (NCDPH) was awarded $\$ 7.4$ million in federal funds through a 5-year implementation award as part of the Community Transformation Grant (CTG) Project. One of the 5 North Carolina CTG Project priority areas is increasing access to fruits and vegetables via enhancements to and creation of new farmers' markets in North Carolina counties. Market enhancements include creating or enhancing land use protections to support markets, improving the physical structure of markets, increasing transportation to and from markets, implementing SNAP/EBT at markets, and increasing nutrition education opportunities and market promotional activities.

\section{The North Carolina Fruit and Vegetable Outlet Inventory Tool}

The primary tool used to gather data on existing farmers' markets was the North Carolina Fruit and Vegetable Outlet Inventory (NC FVOI) Tool. The NC FVOI was adapted from the North Carolina Farmers' Market Community Assessment \& Planning Tool (FMCAPT), which was developed by NCDPH's Physical Activity \& Nutrition Branch and used in a 2008-2009 initiative, the North Carolina Childhood Obesity Prevention Demonstration Project. Paper and electronic collection versions of the NC FVOI were initially developed and reviewed by local health department representatives and nutrition faculty at East Carolina University. The tool was revised based on reviewers' feedback and then loaded into SurveyMonkey (SurveyMonkey Inc., Palo Alto, CA). Reviewers then piloted the electronic survey and additional edits were made.

Once finalized, NCDPH trained local health department staff, including CTG Project Regional Staff and Health Department Healthy Communities staff, on the inventory collection process and submission of data using the 
electronic survey. In order to aid them in identifying where some markets were likely located, these local staff members were provided with a list of outlets compiled using the U.S. Department of Agriculture's (USDA) Farmers Market Directory and listings from North Carolina Farm Fresh and LocalHarvest. ${ }^{32,33}$ North Carolina Farm Fresh is a web-based directory of farmers' markets, roadside farmers stands, and pick-your-own farms in North Carolina and is maintained by North Carolina Department of Agriculture \& Consumer Services. ${ }^{32}$ LocalHarvest is a web-based directory of farmers' markets, farms, and other sources of local produce throughout the nation that is maintained by LocalHarvest, Inc. ${ }^{33}$

The trained staff from local health departments then completed the NC FVOI for the 100 North Carolina counties. Statewide, the NC FVOI included data for 692 farmers' markets and 120 community-supported agriculture (CSA)/produce buying clubs, for a total of 812 fruit and vegetable outlets. These data included market owner contact information, location, hours of operation, and payment options at the market, which included whether the market accepted SNAP/EBT. The data were collected August to September 2012. We did not include the data on CSAs in the analysis below because they do not fall within our definition of farmers' market, because they often require preordering and do not usually sell produce onsite.

The 2012 NC FVOI data include a number of different outlet categories that were defined by the data collectors and include farmers' markets, roadside markets, roadside stands, farm stands, tailgate markets, and other similar outlets. It also contains yes/no responses as to whether the outlet was a CSA/buying club. All of the CSAs/buying clubs were tallied and the remaining outlets were aggregated together as farmers' markets for each North Carolina county. Members of the research team verified the location of farmers' markets using 2 methods: Internet searches to confirm the county associated with each town and ZIP code listed for each market and geographic information systems to geocode the market locations. The study was approved by the Institutional Review Boards of East Carolina University and the University of North Carolina at Chapel Hill.

\section{County-Level Rural and Urban Status}

We examined 3 separate classifications of rurality. For the first classification of rural/urban status, the CTG Project's rural/urban distinction based on metropolitan statistical areas (MSAs) was examined. This is a dichotomous variable of metropolitan and micropolitan status as defined by the White House Office of Management and Budget. ${ }^{34}$ In North Carolina, there are 40 counties that are part of an MSA and 60 that are not.

For the second classification of rural/urban status, the Rural to Urban Continuum Codes from 2013 were examined as another indicator of urban/rural status. ${ }^{34}$ The 2013 Rural-Urban Continuum Codes are an 
extension of the Office of Management and Budget's MSA system. Under this system, "metropolitan" is subdivided in 3 codes and "micropolitan" is subdivided into 6 codes, for a total of 9 codes. ${ }^{35}$ Finally, the percentage of the total population of each county represented by the rural population was also used as a continuous variable. Data for this variable were drawn from the 2010 U.S. Census. ${ }^{36}$ We used these 3 rurality classifications in separate analyses and results for each are presented below.

\section{County-Level Economic Status}

Two methods were used to characterize socioeconomic status of county residents: (1) the percentage of county residents living in poverty in 2010, as defined by the Census Bureau, ${ }^{37}$ and (2) the county tier designation of economic well-being, as assigned by the 2011 North Carolina Department of Commerce. The Department of Commerce annually ranks counties from 1 to 3 according to a formula that takes into account each county's unemployment rate, median household income, population growth, assessed property value per capita, and the percentage of people living below the federal poverty level. Counties that are designated Tier 1 are the most distressed, and Tier 3 counties are the least distressed. ${ }^{38}$ These 2 classifications of socioeconomic status were used in separate analyses and results for each are presented below.

\section{County-Level Racial/Ethnic Minority Status}

For each county, we also determined the percentages of African American residents, Hispanic/Latino residents, and Native American/American Indian residents from the 2010 U.S. Census. ${ }^{39}$ We used these percentages as separate independent variables in the analyses below.

\section{County Level Obesity and Adult Diabetes Prevalence}

The prevalence of adults who were diabetic in 2010 and the prevalence of adults who were obese in 2010, as well as the low-income preschool obesity prevalence from 2009 to 2011 for each North Carolina county, were obtained from the USDA Food Environment Atlas. ${ }^{30}$ The data sources for these variables in the USDA Food Environment Atlas include the Pediatric Nutrition Surveillance System and the Behavioral Risk Factor Surveillance System.

\section{Statistical Analysis}

Univariate descriptive statistics (means and standard deviations) were used to examine county-level rural/urban status, economic status, and racial and 
ethnic minority status, as well as county-level childhood and adult obesity and adult diabetes rates. Pearson's correlation coefficients were used to examine associations between the number of farmers' markets, markets per capita, markets accepting SNAP/EBT, and markets accepting SNAP/EBT per capita and our continuous independent variables of percentage rural residents, percentage living at or below the federal poverty level, and percentage racial/ethnic minority.

We used Poisson regression analyses to examine the relationship between the total number of farmers' markets and farmers' markets accepting SNAP/EBT and the continuous independent variables mentioned above. We used linear regression analyses to examine the relationship between the per capita number of farmers' markets and the per capita number of farmers' markets accepting SNAP/EBT and these same continuous independent variables. For the 2 sets of categorical independent variables (MSA status, county tier designation), Poisson regression (adjusted for county population) was used to examine differences in absolute numbers of farmers' markets and number of farmers' markets that accept SNAP/EBT in the counties. Linear regression (adjusted for county population) was also used for these categorical variables to examine differences in the number of farmers' markets per capita and the number of farmers' markets that accept SNAP/EBT per capita in the counties among categorical variables (MSA status, county tier designation). The $P$ values and confidence intervals for these categorical variable analyses were adjusted for multiple comparisons using the Tukey-Kramer method.

Finally, linear regression analyses were used to examine the association between dependent variables of county-level obesity prevalence (adult and child) and diabetes rate and the independent variables of number of markets, markets per capita, number of markets accepting SNAP/EBT, and number of markets accepting SNAP/EBT per capita. These linear regression analyses included independent variables for county population, percentage rural residents, percentage living at or below the federal poverty level, and percentage racial/ethnic minority. All analyses were conducted at the county level in SAS version 9.3 (SAS Institute, Cary, NC).

\section{RESULTS}

The first section below provides descriptive data about the availability of farmers' markets and SNAP/EBT, and the second section summarizes the results from our Poisson and linear regression analyses. The remaining sections describe the results as they relate to our specific hypotheses about the relationship between farmers' market and SNAP-EBT system availability and levels of rurality, poverty, minority status, and obesity and diabetes prevalence. 


\section{Farmers' Market and SNAP/EBT Availability}

The collected data indicate that the mean number of farmers' markets per county was $6.92(\mathrm{SD}=4.77)$ with a range of 0 to 23 markets per county. The mean number of farmers' markets per capita was 1.5 markets per 10 000 people $(\mathrm{SD}=1.44)$, with a range of 0 to 8.6 per 10000 people. The mean number of farmers' markets accepting SNAP/EBT was 0.83 per county $(\mathrm{SD}=1.31)$, with a range from 0 to 5 markets per county. Overall, roughly $12 \%$ of the farmers' markets surveyed reported that they accept SNAP/EBT. The proportion of farmers' markets that accept SNAP/EBT in each county ranged from $0 \%$ to $67 \%$.

\section{Regression Analyses}

Using Poisson regression analyses, we found that the percentage of African American residents was inversely associated with the number of farmers' markets (estimate $=-0.0144$ [standard error $=0.0032$ ], $P<.001$ ), the county population per 10000 was positively associated with the number of markets (0.0083 [0.0026], $P=.002$ ), and the percentage of the population in the county that lived in rural areas was inversely associated with the number of markets $(-0.0089$ [0.0018], $P<.001)$.

When the number of markets accepting SNAP/EBT was the dependent variable, there was an inverse association between percentage of African American residents and SNAP/EBT availability (estimate $=-0.0273$ [0.0096], $P=.004)$, a positive association between county population and the number of markets accepting SNAP/EBT $(0.0252$ [0.0063], $P<.001)$, and an inverse association between the percentage of the population in the county that lived in rural areas and the number of markets that accept SNAP/EBT $(-0.0106$ [0.0054], $P=.049$ ).

Using linear regression analysis with number of farmers' markets per capita as the dependent variable, only county population per 10000 was positively associated with the number of markets $\left(2.5 \times 10^{-6}\left[6.0 \times 10^{-7}\right]\right.$, $P<.001)$. Nothing was significant when the number of markets accepting SNAP/EBT per capita was the dependent variable.

In separate adjusted linear regression analyses with adult obesity, adult diabetes, and low-income preschool obesity prevalence as dependent variables and number of farmers' markets, markets per capita, markets with EBT, and markets with EBT per capita as independent variables, there were no significant associations found.

Availability of Farmers' Markets and County-Level Rural and Urban Status

Table 1 shows Pearson correlations between number of farmers' markets, markets per capita, markets accepting SNAP/EBT, markets accepting 


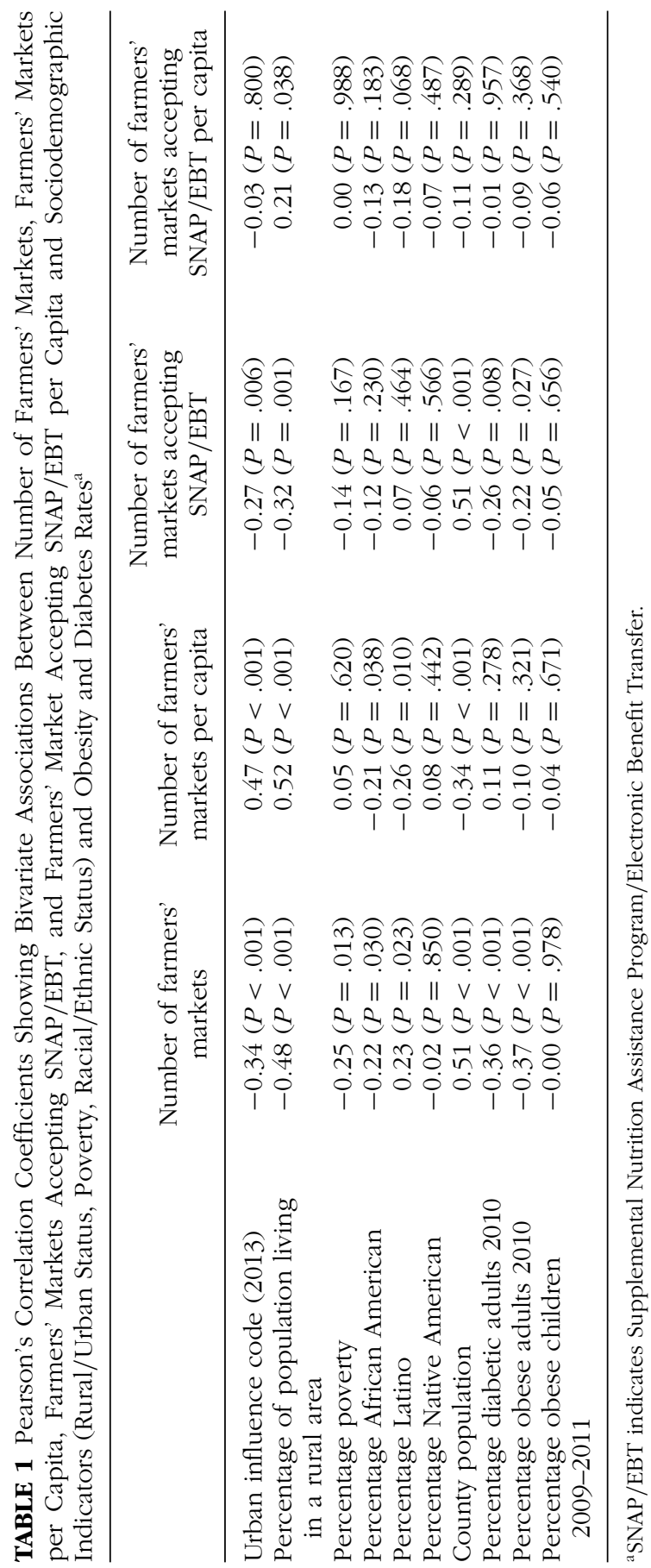


SNAP/EBT per capita, and sociodemographic indicators (rural/urban status, poverty, racial/ethnic status) and obesity and diabetes rates. The number of farmers' markets and the number of farmers' markets accepting SNAP/EBT were both inversely associated with rural to urban continuum codes and percentage residents living in rural areas. Thus, we found a fewer total number of farmers' markets and markets that accept SNAP/EBT in more rural counties. The number of farmers' markets per capita, however, was positively associated with rural to urban continuum codes and percentage residents living in rural areas. Thus, there were more farmers' markets per capita in rural counties. The number of markets accepting SNAP/EBT per capita was not significantly associated with rural to urban continuum codes but was positively associated with percentage residents living in rural areas.

Table 2 shows the mean number and standard deviation of farmers' markets, markets per capita, markets accepting SNAP/EBT, and markets accepting SNAP/EBT per capita by MSA designation, and economic tier status. Using the MSA distinction, metro counties had, on average, 8.3 (SD = 5.9) farmers' markets and nonmetro counties had a mean of 6.0 ( $\mathrm{SD}=$ 3.6) farmers' markets. The mean number of markets per 10000 people in metro counties was $1.0(\mathrm{SD}=1.0)$ and was $1.8(\mathrm{SD}=1.5)$ in nonmetro counties. Under a Poisson regression, the average number of farmers' markets was significantly higher $(P<.001)$ in metro counties than in nonmetro counties. The number of farmers' markets that accept SNAP/EBT was also significantly higher $(P=.017)$ in metro counties than in nonmetro counties. Under a linear regression, the number of farmers' markets per capita was significantly lower $(P=.001)$ in metro counties than in nonmetro counties. For markets accepting SNAP/EBT, per capita the difference between metro and nonmetro counties was not significant.

\section{Availability of Farmers' Markets and County-Level Economic Status}

Table 1 also suggests an inverse association between percentage of residents living below poverty and the total number of farmers' markets, such that counties with more residents living below poverty had fewer total number of farmers' markets. There were no significant associations between percentage of residents living below poverty and the number of markets that accept SNAP/EBT, number of farmers' markets per capita, or number of markets that accept SNAP/EBT per capita.

Table 2 shows that Tier 1 counties (most distressed) had a mean of 5.3 $(\mathrm{SD}=3.9)$ farmers' markets, Tier 2 counties had $6.7(\mathrm{SD}=3.8)$ markets, and Tier 3 had 10.7 (SD = 6.1) markets. Under a Poisson regression, there were significant differences in the number of markets between the tiers $(P<$ .001). The trend of increasing availability was also apparent for access to SNAP/EBT. Under a Poisson regression, the differences in farmers' markets with SNAP/EBT access between Tier 3 and Tier 1 and Tier 3 and Tier 2 were 


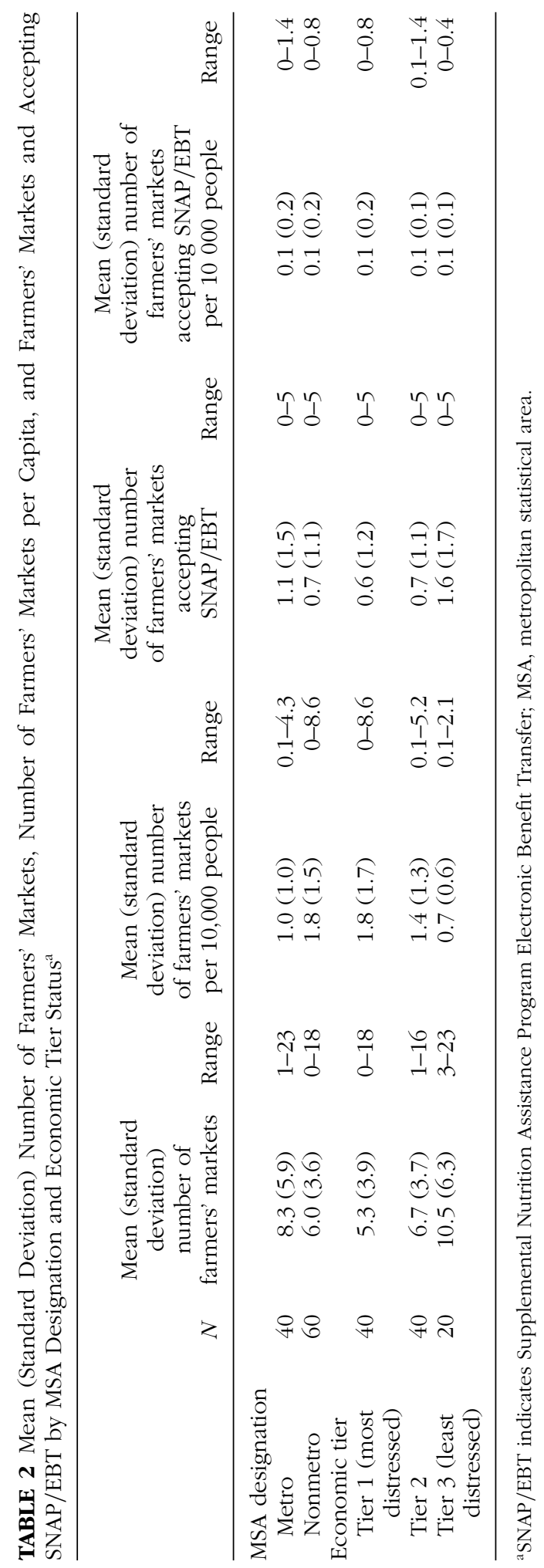


also significant $(P<.001)$. In contrast, Table 2 shows that per capita, there were more farmers' markets in Tier 1 than in Tiers 2 and 3. Under a linear regression, the differences in farmers' markets per capita was only significant $(P=.013)$ between Tiers 1 and 3. For markets that accept SNAP/EBT, per capita there were no significant differences between the different tiers.

\section{Availability of Farmers' Markets and County-Level Racial/Ethnic Minority Status}

There were significant negative associations between both the number of farmers' markets and the number of farmers' markets per capita and the population percentage of African Americans. There was a significantly positive association between the total number of farmers' markets and percentage of Latino residents. In contrast, there was a significantly negative association between the number of farmers' markets per capita and percentage of Latino residents. There were no significant associations between Native American/American Indian county residents and the total number of farmers' markets or farmers' markets per capita (Table 1).

\section{Availability of Farmers' Markets and County-Level Diabetes and Obesity Rates}

The number of farmers' markets and markets that accept SNAP/EBT was inversely associated with adult obesity and adult diabetes rates but not with obesity rate among children (Table 1).

\section{DISCUSSION}

One of the primary goals of this study was to examine the availability of farmers' markets and farmers' markets that accept SNAP/EBT in rural and urban counties in North Carolina. Because decisions about how to define rural and urban areas can influence analysis outcomes and subsequent programmatic and policy recommendations, ${ }^{40,41}$ we examined 3 different classifications of county-level rural and urban status for North Carolina counties. We also examined 2 different measures of farmers' market availability, the absolute number of farmers' markets, and the number of farmers' markets per capita in each county. The analyses that examined associations between the absolute number of farmers' markets and the different urban/rural classifications suggest that rural residents in North Carolina may have less access to farmers' markets overall and less access to farmers' markets that accept SNAP/EBT than their urban counterparts. However, the analyses that examined associations between the number of farmers' markets per capita and 
the different urban/rural classifications suggest the opposite conclusionrural residents may have more access to farmers' markets and more access to farmers' markets that accept SNAP/EBT than their urban counterparts.

These mixed results might be explained by several factors. Rural areas are centers of agricultural production and it would therefore seem logical that these areas should have greater access to local sources of produce than urban areas. This would explain the higher per capita levels of farmers' markets in rural areas. However, the sparse populations and higher levels of poverty that can be found in rural communities may make farmers' markets less financially viable in rural areas than in urban areas. In addition, much of the land in some rural counties may be devoted to animal agriculture and/or commodity crops-such as tobacco, cotton, soybeans, and cornrather than fresh produce. There may also be a lack of demand for farmers' markets in some counties due to social and cultural factors. Efforts to educate citizens about the importance of produce may also not be as well-funded and visible in counties where markets are less commonly found. These factors would explain our finding that the absolute number of farmers' markets was lower in rural areas, which is consistent with studies that have found that rural residents have less access to supermarkets and grocery stores than residents of more urban areas ${ }^{14-19}$ (we are not aware of other studies that have specifically compared the availability of farmers' markets in rural and urban areas).

Issues around how to define and measure availability and access to farmers' markets in counties may also explain these mixed results. Both the absolute number and the per capita number of farmers' markets in counties have limitations as measures of farmers' market availability. For example, our data set does not allow us to distinguish between markets with just one vendor and markets with several vendors. As a result, it is difficult to determine whether a rural county with 5 smaller markets has greater market availability than a more urban county with 3 large markets. This raises a related question about the capacity of farmers' markets- how many patrons can each market support? Though our data indicate that urban counties have fewer farmers' markets per capita than rural counties, if the markets in urban areas have a larger capacity because they have greater variety of items or more vendors, then the per capita number of markets may not be a very meaningful measure.

In addition, the use of counties as the unit of analysis raises methodological issues as well-residents of one county may have access to a nearby farmers' market that is located within a neighboring county. The distribution and concentration of the markets within each county is also an important issue to consider. For example, a county may have several farmers' markets, but if they are all concentrated in one or a few areas within the county, some residents may need to travel much further than others to access a market. These factors should be considered in future studies that seek to assess farmers' market availability in rural vs. urban areas. 
Our results were also mixed in the context of farmers' markets availability and county-level economic status. Counties with more residents living below poverty and counties that are the most economically distressed had a lower total number of markets. This finding is similar to studies that have found fewer supermarkets in predominately low-income communities relative to higher income communities. ${ }^{17,42-44}$ In contrast, there were more farmers markets per capita in the most economically distressed counties compared to the least distressed counties, but there were no significant associations between residents living below poverty and the number of farmers' markets per capita.

We also found that the most economically distressed counties had fewer farmers' markets that accept SNAP/EBT relative to the least distressed counties, but there were no significant associations for the number of markets that accept SNAP/EBT per capita. Though we might expect counties with higher levels of low-income residents to have greater access to SNAP/EBT, we did not find that to be the case in our study, and overall in North Carolina only a small percentage of the markets accept SNAP/EBT. The low number of markets that accept SNAP/EBT could be explained by the fact that there are a number of barriers that can make it difficult for famers' markets to provide access to SNAP/EBT. ${ }^{31}$ For example, if farmers' markets are not equipped with a telephone line and electricity, they must use wireless EBT systems that can be costly to purchase and maintain. ${ }^{28,31,45}$ If SNAP sales are not high enough to cover the costs of the initial investment in the wireless system, it may not be a viable option for individual farmers or market organizers. ${ }^{31}$

Our findings related to African American access to farmers' markets more consistently support our hypotheses. The number of farmers' markets and the number of farmers' markets per capita were both lower in counties with higher percentages of African Americans residents. These findings are consistent with other studies that have found that predominantly African American communities often have less access to healthy foods relative to nonminority communities. ${ }^{17,44,46,47}$ For example, a study conducted in New York City that examined the density of "healthy food outlets," including supermarkets, fruit and vegetable markets, and farmers' markets, found fewer healthy food outlets in predominantly African American census tracts. ${ }^{48}$ However, the results for Latino residents was once again mixed-the total number of farmers' markets was positively associated with the percentage of Latino residents, whereas the number of farmers' markets per capita was negatively associated with the percentage of Latino residents. The methodological issues cited above may also explain these divergent results.

Unlike other studies that have found associations between proximity to farmers' markets and obesity, ${ }^{49,50}$ in adjusted linear regression analyses, we did not find such associations. The lack of associations between farmers' market availability and SNAP/EBT availability at markets and county-level diabetes and obesity prevalence may also be due to the methodological 
issues cited above. It may also be due to the need to measure other food environment exposures in tandem with exposure to farmers' markets. The scope of our study did not allow us to measure all sources of healthy food in North Carolina counties, and there may be other sources of healthy food in the counties with fewer farmers' markets. For example, home gardening or crop sharing among neighbors may exist in more rural counties or counties with less access to farmers' markets. We also did not measure physical activity levels among residents of the different counties, which may be a confounder in the relationship between farmers' markets and diabetes and obesity in North Carolina.

\section{Limitations}

The findings of this analysis should be interpreted with caution. In addition to the limitations mentioned above regarding the absolute number and per capita farmer markets' metrics, the ecological study design and the crosssectional nature of the data are limitations. Furthermore, the NC FVOI data were collected by different individuals in different counties, with different training and job descriptions, and so there may be errors due to these differences in the background and experience of our data collection personnel. The SNAP/EBT data are self-reported by the farmers' market managers or points of contact at the time of data collection and therefore may be biased and inaccurate. It was also beyond the scope of our study to collect information on other sources of produce and healthy foods in North Carolina counties. For example, information on home-grown produce was not collected, so the extent to which residents have access to produce that is grown in their own gardens or from other sources is unknown.

\section{CONCLUSIONS}

As far as we are aware, this is the first study to examine potential disparities in county-level access to farmers' markets by socioeconomic and other demographic features. Overall, the results of this study suggest that there may be less access to healthful food sources in predominantly African American communities. The data on the relationship between rurality and socioeconomic circumstances is mixed. Though we found a significant negative association between the total number of farmers' markets and farmers' markets with SNAP-EBT systems and measures of rurality, poverty, and economic distress, we also found a significant positive association between the per capita number of farmers' markets and farmers' markets with SNAP-EBT systems and measures of rurality and economic distress. We did not find associations between farmers' market availability or SNAP/EBT availability at markets and county-level diabetes and obesity prevalence. 
These results suggest that additional research is warranted because of the limitations associated with the scope of our study. This research has identified several methodological challenges that should be addressed in future efforts to assess the relationships between farmers' markets, access to healthy food, and health outcomes. Ideally, all outlets of healthy food should be taken into account-not only farmers' markets but grocery stores, community-supported agriculture and buying clubs, levels of urban and home gardening, and farmer food swapping initiatives. Furthermore, countylevel data are likely insufficient to accurately capture the accessibility of any of these outlets for consumers. Future research should utilize geographic information systems to calculate the distance of healthy food outlets to minor and major population centers. The size and "quality" of these food outletsfor example, types and amount of food sold-should also be taken into account in these analyses.

Despite these limitations, this study provides an important foundation for future research. Results from this study will inform the Community Transformation Grant Project in North Carolina and may help in guiding decisions about the introduction and enhancement of farmers' markets in high need areas. Though our study did not examine demand for farmers' markets in North Carolina counties, efforts may need to be taken to educate residents about the importance of produce and to enhance demand for farmers' markets in counties with fewer markets. These results also indicate that more work should be done to examine barriers to establishing and maintaining farmers' markets in counties with higher percentages of African American residents. Barriers and facilitators to establishing and maintaining farmers' markets and markets with SNAP/EBT access in high poverty areas should also be explored.

\section{ACKNOWLEDGEMENTS}

The authors thank all of the CTG Project Staff for their many contributions to the project.

\section{FUNDING}

This article was supported in part by a cooperative agreement with the Centers for Disease Control and Prevention (FOA CDC-RFA-DP111115PPHF11). Portions of this project's work involve the Communities Transforming initiative supported by CDC funding. However, the findings and conclusions in this article are those of the authors and do not necessarily represent the official position of the Centers for Disease Control and Prevention. Users of this document should be aware that every funding 
source has different requirements governing the appropriate use of those funds. Under U.S. law, no federal funds are permitted to be used for lobbying or to influence, directly or indirectly, specific pieces of pending or proposed legislation at the federal, state, or local levels. Organizations should consult appropriate legal counsel to ensure compliance with all rules, regulations, and restriction of any funding sources.

\section{REFERENCES}

1. Befort CA, Nazir N, Perri MG. Prevalence of obesity among adults from rural and urban areas of the United States: findings from NHANES (2005-2008). J Rural Health. 2012;28:392-397.

2. Davis AM, Bennett KJ, Befort C, Nollen N. Obesity and related health behaviors among urban and rural children in the United States: data from the National Health and Nutrition Examination Survey 2003-2004 and 2005-2006. J Pediatr Psychol. 2011;36:669-676.

3. Jackson JE, Doescher MP, Jerant AF, Hart LG. A national study of obesity prevalence and trends by type of rural county. J Rural Health. 2005;21(2):140-148.

4. Field AE, Coakley EH, Must A, et al. Impact of overweight on the risk of developing common chronic diseases during a 10-year period. Arch Intern Med. 2001;161:1581-1586.

5. Wilson PW, D'Agostino RB, Sullivan L, Parise H, Kannel WB. Overweight and obesity as determinants of cardiovascular risk: the Framingham experience. Arch Intern Med. 2002;162:1867-1872.

6. Must A, Spadano J, Coakley EH, Field AE, Colditz G, Dietz WH. The disease burden associated with overweight and obesity. JAMA. 1999;282:1523-1529.

7. Jones CA, Parker TS, Ahearn M, Mishra AK, Variyam JN. Health Status and Health Care Access of Farm and Rural Populations. U.S. Department of Agriculture, Economic Research Service; 2009. Economic Information Bulletin No. 57.

8. Eberhardt M, Ingram D, Makuc D. Urban and Rural Health Chartbook. Hyattsville, MD: Department of Health and Human Service, Centers for Disease Control and Prevention, National Center for Health StatisticsNational Center for Health Statistics; 2001.

9. Gamm LD, Hutchison LL, Dabney BJ, Dorsey AM. Rural Healthy People 2010: A Companion Document to Healthy People 2010. Vol 1. College Station, TX: The Texas A\&M University System Health Science Center, School of Rural Public Health, Southwest Rural Health Research Center; 2003.

10. Kusmin L. Rural America at a Glance, 2011 Edition. Available at: http:// www.ers.usda.gov/publications/eib-economic-information-bulletin/eib85.aspx\#. UZEpkrWNrzy. Accessed May 13, 2013.

11. Farrigan T, Parker T. The concentration of poverty is a growing rural problem. Available at: http://www.ers.usda.gov/amber-waves/2012-december/ concentration-of-poverty.aspx\#.UZEssLWNrzx. Accessed May 13, 2013.

12. Flegal KM, Carroll MD, Kit BK, Ogden CL. Prevalence of obesity and trends in the distribution of body mass index among U.S. adults, 1999-2010. JAMA. 2012;307:491-497. 
13. Ogden CL, Lamb MM, Carroll MD, Flegal KM. Obesity and socioeconomic status in adults: United States, 2005-2008. Available at: http://www.cdc.gov/nchs/data/ databriefs/db50.pdf. Accessed May 16, 2013.

14. Liese AD, Weis KE, Pluto D, Smith E, Lawson A. Food store types, availability, and cost of foods in a rural environment. J Am Diet Assoc. 2007;107:1916-1923.

15. Larson NI, Story MT, Nelson MC. Neighborhood environments: disparities in access to healthy foods in the U.S. Am J Prev Med. 2009;36:74-81.

16. Morton LW, Blanchard TC. Starved for access: life in rural America's food deserts. Rural Sociol. 2007;1-10.

17. Powell LM, Slater S, Mirtcheva D, Bao Y, Chaloupka FJ. Food store availability and neighborhood characteristics in the United States. Prev Med. 2007;44(3):189-195.

18. Michimi A, Wimberly MC. Associations of supermarket accessibility with obesity and fruit and vegetable consumption in the conterminous United States. Int J Health Geogr. 2010;9:1-14.

19. Kaufman PR. Rural poor have less access to supermarkets, large grocery stores. Rural Development Perspectives. 1999;13(3):19-26.

20. Cheadle A, Psaty BM, Curry S, et al. Community-level comparisons between the grocery store environment and individual dietary practices. Prev Med. 1991;20:250-261.

21. Fisher BD, Strogatz DS. Community measures of low-fat milk consumption: comparing store shelves with households. Am J Public Health. 1999;89:235-237.

22. Morland KB, Evenson KR. Obesity prevalence and the local food environment. Health Place. 2009;15:491-495.

23. Morland K, Diez Roux AV, Wing S. Supermarkets, other food stores, and obesity: the Atherosclerosis Risk in Communities Study. Am J Prev Med. 2006;30:333-339.

24. Caspi CE, Sorensen G, Subramanian SV, Kawachi I. The local food environment and diet: a systematic review. Health Place. 2012;18:1172-1187.

25. Lutfiyya MN, Chang LF, Lipsky MS. A cross-sectional study of US rural adults' consumption of fruits and vegetables: do they consume at least five servings daily? BMC Public Health. 2012;12:1-16.

26. Alfonso ML, Cohen D, Nickelson J. Farmers' markets in rural communities: a case study. Am J Health Educ. 2012;143-151.

27. Young C, Karpyn A, Uy N, Wich K, Glyn J. Farmers' markets in low income communities: impact of community environment, food programs and public policy. Community Dev. 2011;42:208-220.

28. Briggs S, Fisher A, Lott M, Miller S, Tessman N. Real food, real choice: connecting SNAP recipients with farmers markets. Available at: http://cclhdn.org/ wp-content/uploads/2013/02/RealFoodRealChoice_SNAP_FarmersMarkets.pdf. Accessed March 14, 2014.

29. U.S. Census Bureau. Census of Population and Housing, Population and Housing Unit Counts. Available at http://www.census.gov/. Accessed March 23, 2014.

30. U.S. Department of Agriculture, Economic Research Service. Food Environment Atlas. Available at: http://www.ers.usda.gov/data-products/food-environmentatlas/data-access-and-documentation-downloads.aspx. Accessed January 30, 2013 . 
31. U.S. Department of Agriculture. Supplemental Nutrition Assistance Program (SNAP): feasibility of implementing Electronic Benefit Transfer (EBT) systems in farmers' markets. Available at: http://www.fns.usda.gov/multimedia/ Kohl-Feasibility.pdf. Accessed March 14, 2014.

32. Fresh. Availble at: http://www.ncfarmfresh.com/. Accessed March 14, 2014.

33. LocalHarvest Inc. LocalHarvest. Available at: http://www.localharvest.org/. Accessed March 14, 2014.

34. U.S. Department of Agriculture, Economic Research Service. 2004 County typology codes. Available at: http://www.ers.usda.gov/data-products/countytypology-codes.aspx. Accessed January 3, 2013.

35. U.S. Department of Agriculture, Economic Research Service. Rural-urban continuum codes. Available at: http://www.ers.usda.gov/data-products/rural-urbancontinuum-codes/documentation.aspx. Accessed January 3, 2013.

36. U.S. Census Bureau. 2010 Census urban and rural classification and urban area criteria. Available at: http://www.census.gov/geo/reference/urban-rural2010.html. Accessed January 3, 2013.

37. State Center for Health Statistics, N.C. Division of Public Health. Data for percentage of individuals living in poverty by county, 2010. Available at: http:/ /healthstats.publichealth.nc.gov/indicator/view_numbers/Poverty.County.html. Accessed January 30, 2013.

38. North Carolina Department of Commerce. 2011 County tier designations. Available at: http://www.nccommerce.com/research-publications/incentivereports/2011-county-tier-designations. Accessed February 26, 2013.

39. U.S. Census Bureau. State and County Quick Facts. Available at: http://quickfacts. census.gov/qfd/states/37000.html. Accessed February 15, 2013.

40. Hall SA, Kaufman JS, Ricketts TC. Defining urban and rural areas in U.S. epidemiologic studies. J Urban Health. 2006;83(2):162-175.

41. Hart LG, Larson EH, Lishner DM. Rural definitions for health policy and research. Am J Public Health. 2005;95:1149-1155.

42. Alwitt LF, Donley TD. Retail stores in poor urban neighborhoods. J Consum Aff. 1997;31:139-164.

43. Chung C, Myers SL. Do the poor pay more for food? An analysis of grocery store availability and food price disparities. J Consum Aff. 1999;33:276-296.

44. Morland K, Wing S, Diez Roux A, Poole C. Neighborhood characteristics associated with the location of food stores and food service places. Am J Prev Med. 2002;22:23-29.

45. Buttenheim AM, Havassy J, Fang M, Glyn J, Karpyn AE. Increasing Supplemental Nutrition Assistance Program/Electronic Benefits Transfer sales at farmers' markets with vendor-operated wireless point-of-sale terminals. J Acad Nutr Diet. 2012;112:636-641.

46. Zenk SN, Schulz AJ, Israel BA, James SA. Fruit and vegetable access differs by community racial composition and socioeconomic position in Detroit, Michigan. Ethn Dis. 2006;16:275-280.

47. Hall BF. Neighborhood differences in retail food stores: income versus race and age of population. Econ Geogr. 1983;59:282-295. 
48. Bader MD, Purciel M, Yousefzadeh P, Neckerman KM. Disparities in neighborhood food environments: implications of measurement strategies. Econ Geogr. 2010;86:409-430.

49. Jilcott SB, Wade S, McGuirt JT, Wu Q, Lazorick S, Moore JB. The association between the food environment and weight status among eastern North Carolina youth. Public Health Nutr. 2011;14:1610-1617.

50. Jilcott SB, Keyserling T, Crawford T, McGuirt JT, Ammerman AS. Examining associations among obesity and per capita farmers' markets, grocery stores/supermarkets, and supercenters in U.S. counties. J Am Diet Assoc. 2011;111:567-572. 